\title{
The prevalence and clinical importance of an "additional" terminal branch of the left coronary artery
}

\author{
N.O. Ajayi ${ }^{1}$, L. Lazarus ${ }^{1}$, E.A. Vanker ${ }^{2}$, K.S. Satyapal ${ }^{1}$ \\ ${ }^{1}$ Department of Clinical Anatomy, School of Laboratory Medicine and Medical Sciences, College of Health Sciences, \\ Westville Campus, University of KwaZulu-Natal, Durban, South Africa \\ ${ }^{2}$ Specialist Cardio-Thoracic Surgeon, St Augustine's Hospital, Chelmsford Medical Centre 3, Durban, South Africa
}

[Received 6 November 2012; Accepted 23 January 2013]

\begin{abstract}
The left coronary artery (LCA) usually divides into two (anterior interventricular artery $[A I A]$ and left circumflex $[L C X]$ artery) or less frequently into the $A I A, L C X$, and one or more "additional" terminal branchles (ATBS). These ATBs of the LCA have no unanimity regarding their anatomical nomenclature. There is a lack of common consensus on the criteria used for their definition, and they are also absent from the current Terminologia Anatomica (1998). This study, therefore, aimed to document the prevalence of the ATBs of the LCA, discuss their clinical importance, and propose an anatomical nomenclature. This study was conducted by reviewing 367 coronary angiograms. The termination patterns of the LCA were classified into 3 categories based on the number of their branches, viz. (a) bifurcation $78.2 \%$, (b) trifurcation $20.4 \%$, and (c) quadrifurcation $1.4 \%$, respectively. The presence of an ATB was recorded in $21.8 \%$ of the angiograms. The identification of this vessel may be of clinical importance because the extent of its supply may decrease the effect of occlusion of the LCX artery and AIA on the myocardium. The term "left ramus medianus artery" is proposed as the nomenclature for the ATB of the LCA. (Folia Morphol 2013; 72, 2: 128-131)
\end{abstract}

Key words: left coronary artery, branching pattern, nomenclature, "left ramus medianus artery"

\section{INTRODUCTION}

The arterial supply of most of the heart is dependent on the patency of the left coronary artery (LCA) [19]. On reaching the atrioventricular groove, the LCA usually divides into 2 (anterior interventricular artery $[\mathrm{AIA}]$ and left circumflex $[\mathrm{LCX}]$ artery) or less frequently into the AIA, LCX, and one or more "additional" terminal branch/es (ATBs). It is these ATBs (1 or more) that are the topic of investigation and discussion in this paper. There is great variability in the morphometric and morphologic parameters of the LCA with regard to its length, calibre, angle of division, and branching pattern [7].

Although the description of the LCA and its branches have been the topic of repeated anatomical investigation, it is surprising to find that there is no unanimity in the literature regarding the nomenclature of the ATBs of the LCA (when present). There is also a lack of consensus on the criteria used for their definition [16], and these ATBs are

Address for correspondence: Prof. K.S. Satyapal, Department of Clinical Anatomy, School of Laboratory Medicine and Medical Sciences, College of Health Sciences, Westville Campus, University of KwaZulu-Natal, Private Bag X54001, Durban, 4000, South Africa, tel: +2731260 7899, +27837778780,fax: +2731260 7890, e-mail: satyapalk@ukzn.ac.za 


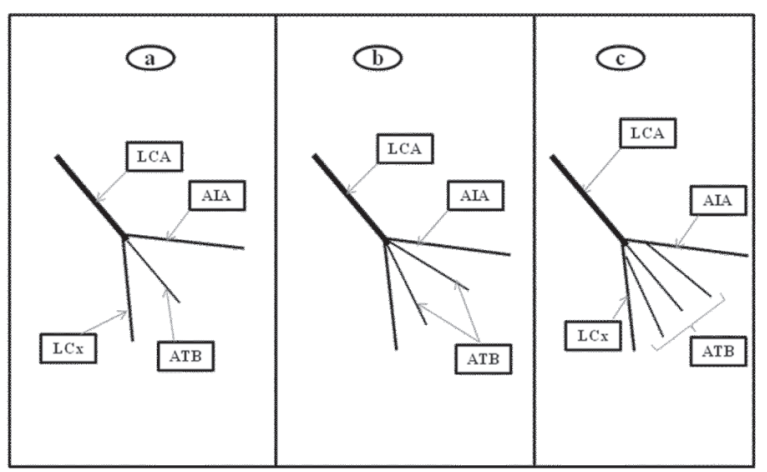

Figure 1A-C. Schematic diagram illustrating the varying definition of the "additional" terminal branch of the left coronary artery (LCA); A, B. "Additional" terminal branch from the vertex of the angle formed by the anterior interventricular artery (AIA) and left circumflex artery (LCX); C. "Additional" terminal branch from the vertex of the angle formed by the AIA and LCx and the proximal segments of the AIA and LCx artery; ATB — additional terminal branch.

absent from the current Terminologia Anatomica (1998) [9]. Furthermore, the nomenclature of these branches has not been afforded much attention in standard anatomical textbooks $[15,20,21]$. However, in anatomical studies these branches have been referred to as the "ramus diagonalis" [3], "median (or intermedian)" branch $[8,19,24]$, and "diagonal branch" [17].

In clinical textbooks, these ATBs are named the "ramus medianus artery" [23] or the "ramus intermedius branch" [22]. The bifurcation of the LCA into the AIA and LCX arteries is the most common branching pattern, while the trifurcation of the LCA into the AIA, LCX artery, and an ATB is described as a variation of its branching pattern [24]. The branching of the LCA into 4 or 5 branches has also been reported in the literature $[4,11]$.

Some authors define the ATB as the artery located at the vertex of the angle formed by the AIA and LCX arteries (Figs. 1A, B) [6, 12-14, 19], while the vessels not at this vertex are considered as collateral branches of the AIA and the LCX arteries. Other authors used a wider definition and considered the ATB as the vessel that originated in the vertex of the angle formed by the terminal branches of the LCA, including the initial length of the AIA and LCX artery (Fig. 1C) [3]. This study aimed to record the prevalence of ATB of the LCA, discuss its clinical importance and propose an anatomical nomenclature based on the origin of the ATB.

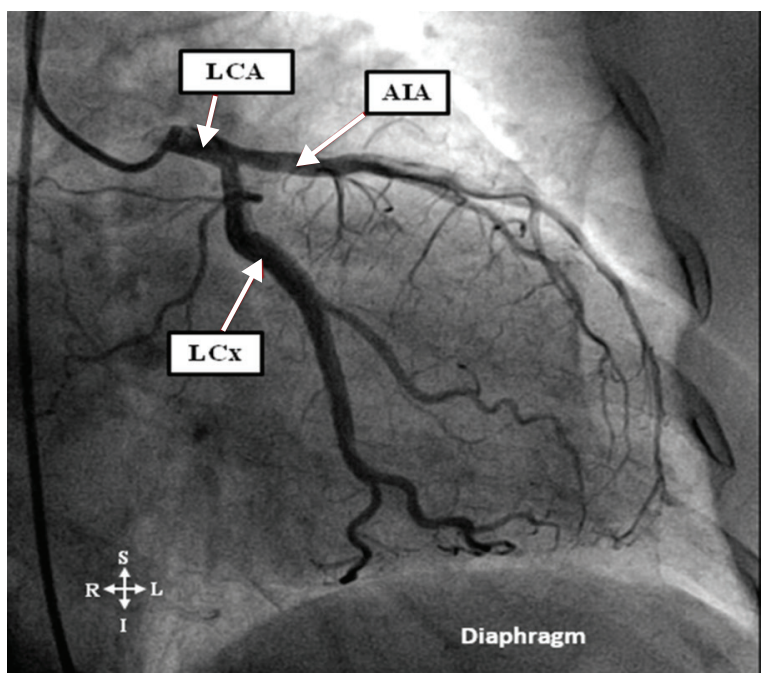

Figure 2. Coronary angiogram in the right anterior oblique projection showing bifurcation of the left coronary artery (LCA) into anterior interventricular artery (AIA) and left circumflex (LCX) artery.

\section{MATERIALS AND METHODS}

A total of 407 coronary angiograms were obtained from cardiac catheterisation laboratories in the eThekwini Metropolitan area, KwaZulu Natal, South Africa. The coronary angiograms without LCA (with branches originating directly from the left aortic sinus) $(n=39)$ and 1 of the angiograms with a poor image of the LCA were excluded. Consequently, a total of 367 angiograms were analysed by 2 independent observers. The branching patterns of the LCA were noted and documented. In this study, the ATB of the LCA was defined as the vessel that originated from the vertex of the angle between the AIA and LCX artery (Figs. 1A, B).

\section{RESULTS}

After excluding the coronary angiograms with absent $L C A$, the remaining angiograms $(n=367)$ were analysed. The incidences of the branching patterns were (i) $287 / 367$ (78.2\%), 75/367 (20.4\%), and 5/367 (1.4\%) for bifurcation (Fig. 2), trifurcation (Fig. 3), and quadrifurcation (Fig. 4) patterns, respectively (Table 1).

\section{DISCUSSION}

There is substantial variation in the incidence of the ATB of the LCA reported in the literature (19-60\%) (Table 1). This may be due to the inconsistent definition of the ATB by different authors [19]. In this study, the branching pattern of the LCA into its 2 terminal branches, viz. the AIA and LCX artery, was classified as the bifurcation pattern $(n=287 / 367$ [78.2\%]). The presence 


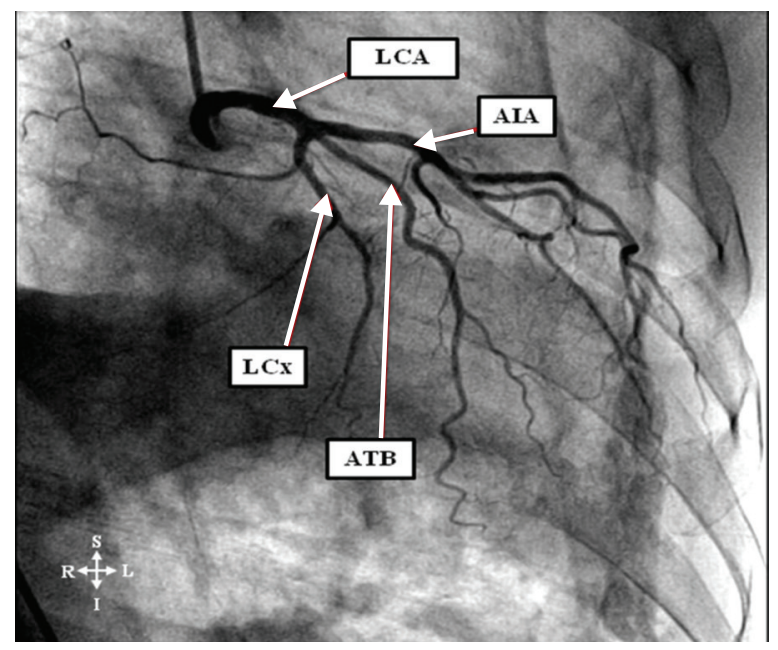

Figure 3. Coronary angiogram in the right anterior oblique projection showing trifurcation of the left coronary artery (LCA) into anterior interventricular artery (AIA), left circumflex (LCX) artery, and an "additional" terminal branch (ATB).

of an ATB (originating from the vertex of the angle formed by the AIA and LCX artery) was classified either as a trifurcation pattern $(n=75 / 367[20.4 \%]-$ for 1 ATB) or a quadrifurcation pattern $(n=5 / 367[1.4 \%]-$ for 2 ATBs). The incidence of $20.4 \%$ recorded for the trifurcation pattern of the LCA compared favourably with the range of $14-60 \%$ reported in the literature, while an incidence of $1.4 \%$ for the quadrifurcation of the LCA in this study was lower than the range of $2-10 \%$ recorded in the literature (Table 1).

The trifurcation of the LCA usually has no adverse haemodynamic effects and may play a protective role against the development of myocardial ischaemia [1].

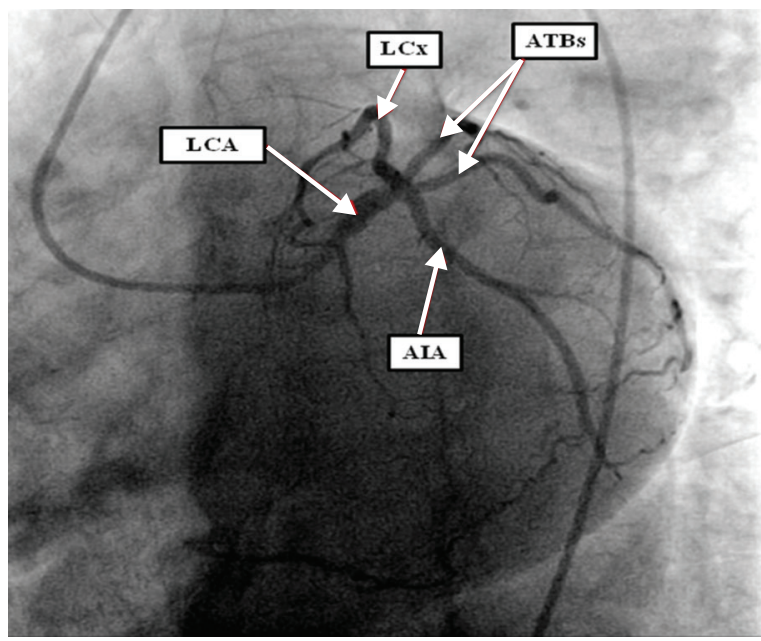

Figure 4. Coronary angiogram in the left anterior oblique projection (caudal view) showing the quadrifurcation of the left coronary artery (LCA) into the anterior interventricular artery (AIA), left circumflex (LCX) artery, and 2 "additional" terminal branches (ATBs).

However, it may cause technical difficulties in coronary artery catheterisation and therefore be a source of complication or misdiagnosis [13]. In cases of myocardial infarction, failure to recognise the occlusion of an ATB may cause misinterpretation of coronary angiograms [10].

The blood supply to the sterno-costal surface of the left ventricle may be through an ATB [16]. It may also give off 1 or more anterior septal arteries and supply the anterior papillary muscle of the left ventricle. In certain cases, and depending on its distribution, the ATB may be an important source of collateral circulation $[16,24]$. The identification of this vessel may be of clinical importance because the extent of

Table 1. Incidence of the branching patterns of the left coronary artery

\begin{tabular}{lcccc}
\hline Author (year) & Sample size & \multicolumn{3}{c}{ Number of branches and percentage } \\
\cline { 3 - 5 } & & $\mathbf{2}(\%)$ & $\mathbf{3}(\%)$ & $\mathbf{4}(\%)$ \\
\hline Crainicianu (1922) & 200 & 38 & 60 & 2 \\
Kalbfleisch and Hort (1976)* & & 41 & 53 & 6.7 \\
Baptisa et al. (1991) [3] & 150 & 54.7 & 38.7 & - \\
Lujinović et al. (2005) [14] & 120 & 71 & 29 & - \\
Kilic and Kiriki (2007) [12] & 50 & 86 & 14 & - \\
Ballesteros and Ramirez (2008) [2] & 154 & 52 & 42.2 & \\
Kosar et al. (2009) [13] & 700 & 69 & 31 & 19 \\
Christensen et al. (2010) [6] & 105 & 81 & 44 & 10 \\
Fazliogullari et al. (2010) [8] & 50 & 46 & 20.4 & 1.4 \\
Present study & 367 & 78.2 & \\
\hline
\end{tabular}

*Cited by Rieg and Petit (2004) 
its supply may decrease the effect of occlusion of the AIA and LCx artery on the myocardium [18].

Cademartiri et al. [5] recorded a prevalence of $21.9 \%$ for the ATB of the LCA. They reported an association of the presence of ATB with decreased number of diagonal branches of the AIA and stressed the importance of the ATB in the vascular supply of the myocardium. The present study found the presence of ATBs of the LCA present in $21.8 \%$ (trifurcation [20.4\%] and quadrifurcation [1.4\%] patterns) of the angiograms. Therefore, the division of the LCA into more than 2 terminal branches is not an infrequent branching pattern. Consequently, based on these findings, the term "left ramus medianus artery" is proposed as the nomenclature for the additional branches of the LCA. This is based on the fact that these additional branches of the LCA are regarded as median branches (i.e. they originate from the vertex of the angle formed by the AIA and LCx artery) of the LCA. Furthermore, in cases where there are more than one ATB, they may be distinguished by adding the suffix I, II, and III for the third, fourth, and fifth branches of the LCA, respectively, starting from the vessel closest to the AIA.

\section{CONCLUSIONS}

This study illustrated that the presence of the ATBs (21.8\% [trifurcation and quadrifurcation]) is not an unusual branching pattern of the LCA. These ATBs may be a source of complication or misdiagnosis. The term "left ramus medianus artery" is recommended to be applied to the one or more ATBs as this may be helpful in standardising the nomenclature of this important additional branch of the LCA.

\section{REFERENCES}

1. Abuchaim DCS, Spera CA, Faraco DL, Ribas Filho JM, Malafaia O (2009) Coronary dominance patterns in the human heart investigated by corrosion casting. Rev Bras Cir Cardiovasc, 24: 514-518.

2. Ballesteros LE, Ramirez LM (2008) Morphological expression of the left coronary artery: a direct anatomical study. Folia Morphol, 67:135-142.

3. Baptista CA, Di Dio L, Prates JC (1991) Types of division of the left coronary artery and the ramus diagonalis of the human heart. Jpn Heart J, 32: 323-335.

4. Bhimalli S, Dixit D, Siddibhavi M and Shirol VS (2011) A study of variations in coronary arterial system in cadaveric human heart. World J Sci Tech, 1: 30-35.

5. Cademartiri F, La Grutta L, Malagň R, Alberghina F, Meijboom W, Pugliese F, Maffei E et al. (2008) Prevalence of anatomical variants and coronary anomalies in 543 consecutive patients studied with 64-slice CT coronary angiography. Eur Radiol, 18: 781-791.
6. Christensen KN, Harris SR, Froemming AT, Brinjikji W, Araoz P, Asirvatham SJ, Lachman N (2010) Anatomic assessment of the bifurcation of the left main coronary artery using multidetector computed tomography. Surg Radiol Anat, 32: 903-909.

7. Dombe DD, Anitha T, Giri PA, Dombe SD, Ambiye VM (2012) Clinically relevant morphometric analysis of left coronary artery. Int J Biol Med Res, 3: 1327-1330.

8. Fazliogullari Z, Karabulut A K, Unver Dogan N, Uysal I (2010) Coronary artery variations and median artery in Turkish cadaver hearts. Singapore Med J, 51: 775.

9. Federative International Programme on Anatomical Terminologies (1998) Terminlogia anatomica. Thieme Verlag, p. 79.

10. Hakim J and Leesar M (2004) Quadfurcation of the left main coronary artery: double ramus medianus coronary system. Angiology, 55: 109.

11. Kalpana RA (2003) A study on principal branches of coronary arteries in humans. J Anat Soc India, 52: 137-140.

12. Kilic C, Kirici $Y$ (2007) Third branch derived from left coronary artery: the medial artery. Gulhane tip Dergisi, 49: 232-235.

13. Kosar P, Ergun E, Öztürk C, Koşar U (2009) Anatomic variations and anomalies of the coronary arteries: 64-slice CT angiographic appearance. Diagn Interv Radiol, 15: 275-283.

14. Lujinović A, Ovcina F, Voljevica A, Hasanović A (2005) Branching of main trunk of left coronary artery and importance of her diagonal branch in cases of coronary insufficiency. Bosn J Basic Med Sci, 5: 69-73.

15. Moore KL, Dalley AF, Agur AMR (2010) Clinical oriented anatomy. $6^{\text {th }}$ Ed. Lippincott Williams and Wilkins, Baltimore.

16. Nikolic V, Blagojevic Z, Stijak L, Malis M, Parapid GT, Stankovic G, Spasojevic G, Filipovic B (2011) The third branch of the main trunk of the left coronary artery in cercopithecus aethiops sabaeus. Is the nonhuman primate model appropriate? Anat Rec, 294: 1506-1510.

17. Ortale JR, Meciano J, Paccola AM (2005) Anatomy of the lateral, diagonal and anterosuperior arterial branches of the left ventricle of the human heart. Braz J Cardiovasc Surg, 20:149-158.

18. Reig J, Jornet A, Petit M (1994) Anatomical variations of the coronary perfusion as a basis of myocardial vulnerability to coronary artery occlusion. Clin Anat, 7: 315-323.

19. Reig J, Petit M (2004) Main trunk of the left coronary artery: anatomic study of the parameters of clinical interest. Clin Anat, 17: 6-13.

20. Sinnatamby CS (2006) Last's anatomy: regional and applied. $11^{\text {th }}$ Ed. Churchill Livingstone, Edinburgh.

21. Standring $S$, Ellis $H$, Healy JC, Johnson D, Williams $A$ eds. (2005) Gray's anatomy. 39th Ed. Newyork, Elsevier Churchill Livingstone, Philadelphia.

22. Topol EJ, Califf RM, Isner J, Prsytowsky E, Swain J, Thomas J, Thompson P, Young JB, Nissen S (2002) Textbook of cardiovascular medicine. Lippincott Williams and Wilkins, Baltimore.

23. Townsend CM, Beauchamp RD, Evers BM, Mattox LM (2004) Sabiston textbook of surgery, $17^{\text {th }}$ Ed. Elsevier, Philadelphia.

24. Vilallonga JR (2003) Anatomical variations of the coronary arteries: the most frequent variations. Eur J Anat, 7: 29-41. 